\title{
Powering Wireless Sensor Nodes: Primary Batteries versus Energy Harvesting
}

\author{
Maria Teresa Penella, Joan Albesa and Manel Gasulla \\ Instrumentation, Sensors and Interfaces Group, Electronic Engineering Dept. \\ Escola Politècnica Superior de Castelldefels \\ Universitat Politècnica de Catalunya (UPC) \\ Castelldefels, Barcelona, Spain \\ manel.gasulla@upc.edu
}

\begin{abstract}
Wireless sensor networks (WSNs) are increasingly used in many fields. Still, power supply of the nodes remains a challenge. Primary batteries are mainly used but energy harvesting offers an alternative, although not free of problems. This paper compares the use of primary batteries against solar cells. Basic principles are first enunciated, then generic design examples are presented and finally actual deployed nodes of a WSN are illustrated.
\end{abstract}

Primary batteries, energy harvesting, wireless sensor networks, wireless nodes, motes, solar cells.

\section{INTRODUCTION}

Wireless sensor networks (WSNs) have emerged as an available technology to be applied in many fields. The reduction of the power consumption of the network nodes (or motes) and the availability of specific standards have estimulated the interest of both the academic community and industry. Still, several challenges need to be addressed for the full expansion of WSNs; among them, power supply of the nodes.

Power to the nodes is usually provided through primary batteries. However, batteries have a finite energy and need replacement when depleted, which increases the maintenance costs. Additionally, the state of charge (SoC) of a battery cannot be easily determined, so preventive replacement in critical applications prior actual battery depletion can be a must. In some other applications the replacement of batteries can be cost prohibitive or even not feasible. To alleviate these problems, energy harvesting from the ambient has emerged as an alternative to primary batteries. Nevertheless, this solution is not free of problems.

This paper compares both alternatives in order to power wireless sensor nodes. For the sake of simplicity we restrict our comparative to energy harvested by solar cells. The work is structured in three main sections. First, Section II outlines the basic principles to take into account when powering a WSN. Then, Section III presents general design examples that highlight which alternative is better for different scenarios. Finally, Section IV presents three types of implemented nodes in a deployed WSN.

\section{BASIC PRINCIPLES}

\section{A. Nodes}

Fig. 1 shows the basic stages of a wireless node. Sensing block includes one or more sensors. Analog processing matches the sensor output to the digital processor, usually a low-cost microcontroller. Commercial transceivers are used for wireless communication. They transmit in the free-licensed ISM band and can use a proprietary or standard (e.g. IEEE802.15.4) protocol. Power has to be provided to the different stages. Nodes that only relay or receive data can skip functions such as sensing and analog processing.

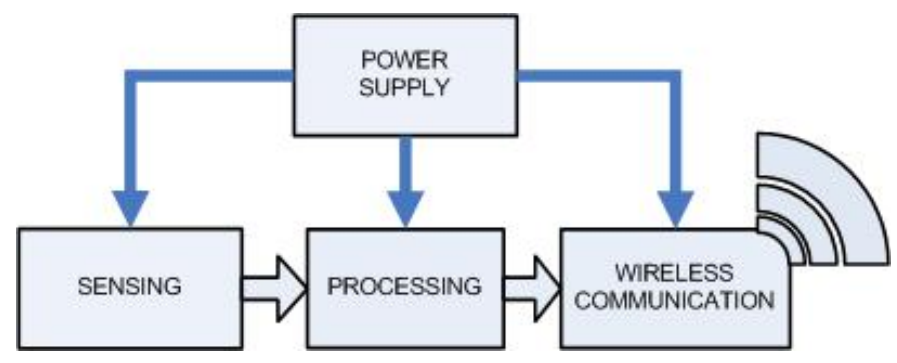

Figure 1. Basic blocks of a wireless node.

Transceivers have been identified as one of the most power hungry parts of a wireless node. Table I shows a list of commercial Zigbee transceivers. As can be seen, power in active mode is four to five orders of magnitude higher than in sleep mode. However, power can also be dominated by the sensor stage [1]. So, new low-power sensors and electronic interfaces can help in the reduction of the power consumption of a sensor node.

\section{TABLE I. COMMERCIAL ZIGBEE TRANSCEIVERS}

\begin{tabular}{|l|c|c|c|}
\hline \multicolumn{1}{|c|}{ Commercial transceivers } & $\boldsymbol{V}_{\text {CC }}(\mathbf{V})$ & $\boldsymbol{P}_{\text {active }}{ }^{\text {a }}(\mathbf{m W})$ & $\boldsymbol{P}_{\text {sleep }}{ }^{\mathbf{a}}(\boldsymbol{\mu W})$ \\
\hline CrossBow, MicaZ OEM & $2.1-3.6$ & 55 & 3 \\
\hline Ember, EM 250/260 & $2.1-3.6$ & 108 & $<3$ \\
\hline FreeScale, MC1320X & $2.0-3.4$ & 100 & $<3$ \\
\hline Jennic, JN513X & $2.2-3.6$ & 102 & 0.6 \\
\hline Atmel, AT86RF230 & $1.8-3.6$ & 48 & 0.3 \\
\hline TI, CC2420 & $2.1-3.6$ & 54 & 0.06 \\
\hline
\end{tabular}

a. Calculated for $\mathrm{Vcc}=3 \mathrm{~V}$.

This work has been funded in part by the Spanish Ministry of Education and Science under contract TEC2007-66331/MIC and by the European Regional Development Fund. M. T. Penella has a grant from the Ministry of Education and Science of Spain on the FPU program (AP2005-2508). Joan Albesa has a FI grant from the Ministry of Innovation, Universities and Enterprise of the Government of Catalonia and the European Social Funding. 
Fig. 2 shows a generic power profile of a node. Average power consumption $\left(P_{\text {average }}\right)$ is given by

$$
P_{\text {average }}=D P_{\text {active }}+(1-D) P_{\text {sleep }}
$$

where $D=t_{\text {active }} / T$ is the duty cycle. $P_{\text {average }}$ can then be lowered by reducing $D$.

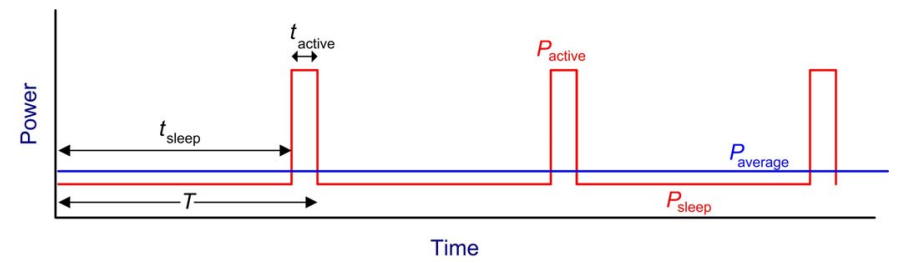

Figure 2. Generic power profile of a node.

\section{B. Power supply}

The power supply stage must be able to provide both the total energy demanded during the expected lifetime and the instant power at the activation time. Fig. 3 shows a generic block diagram of the power supply of a node. The load accounts for the sensing, processing and communication stages in Fig. 1 [2]. The left three blocks make sense when harvesting energy from the ambient; otherwise a primary battery is used (dashed red box). Then, energy harvesting implies a higher circuit complexity. The ensuing power conditioning stage provides the appropriate power supply to the load.

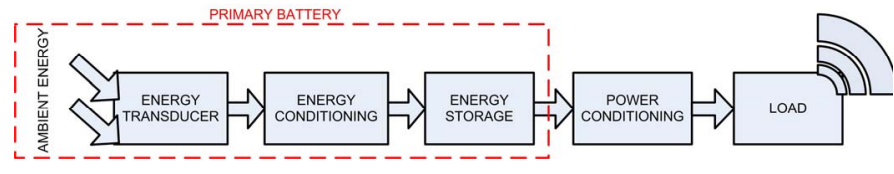

Figure 3. Block diagram of the power supply of a sensor node.

Primary batteries with the appropriate amount of energy must be used to avoid their replacement. Additionally, a supercapacitor can be placed in parallel with the battery to help in providing the required power at the active time [3].

When harvesting the energy from the ambient, the generated power $\left(P_{\mathrm{g}}\right)$ must be higher than that consumed by the node $\left(P_{\mathrm{c}}\right)$, on average. The transducer converts ambient energy into electrical energy, with a given efficiency. Energy storage accounts for the variability of the energy source by either supplying the load or gathering energy from the source. The energy conditioning block is used to properly charge the storage unit. For any arbitrary time period $T$ in which $P_{\mathrm{c}}>P_{\mathrm{g}}$, the storage unit must fulfill the condition

$$
E_{\text {storage }}>\max \left\{\int^{T}\left(P_{\mathrm{c}}-P_{\mathrm{g}}\right) d t\right\} .
$$

Supercapacitors and secondary (rechargeable) batteries can be used as energy storage units. Supercapacitors advantages are lower internal impedance and longer lifetime (in number of charging/discharging cycles). Moreover, remaining energy can be easily measured. However, energy density is much smaller, self-discharge is higher, and output voltage changes more steeply with the extracted or provided charge. Furthermore, the cost per energy is much higher [4]. Hybrid storage units can profit the complementary characteristics of both devices [3].

\section{Batteries versus energy harvesting}

An appropriate metric for primary batteries is their energy density whereas power density seems more appropriate for ambient sources. Energy and power density can be referred to the mass (gravimetric) or to the volume (volumetric). In [4] comprehensive tables and graphs are provided for different power sources and energy storage units.

In order to compare both alternatives, a unique metric must be used. In [5] a graph is presented comparing the power density versus lifetime for different types of batteries and ambient sources. Fig. 4 shows a generic graph of this type. As can be seen, power density of batteries decreases linearly with lifetime because of their limited energy. Energy density mainly depends on battery technology but also on battery size and manufacturer. On the other hand, ambient sources have, on average, a constant power density that depends on the specific ambient source (e.g. optical, mechanical, or thermal) and conditions (e.g. level of the optical radiation or vibration, or temperature gradient). At a specific time, the alternative with the highest power density will provide the best option in terms of size and weight. Regarding to Fig. 4, the considered primary battery or ambient source will be respectively the best option for lifetimes lower or higher than the intersection point between graphs (dashed line). At the other hand, primary batteries have a maximum lifetime (shelf-life) due to selfdischarge and chemical decomposition [6]. Lifetime of energy harvesters can also be limited by the storage unit. Finally, a balance between different constraints (e.g. size, weight, cost, and circuit complexity) can be considered.

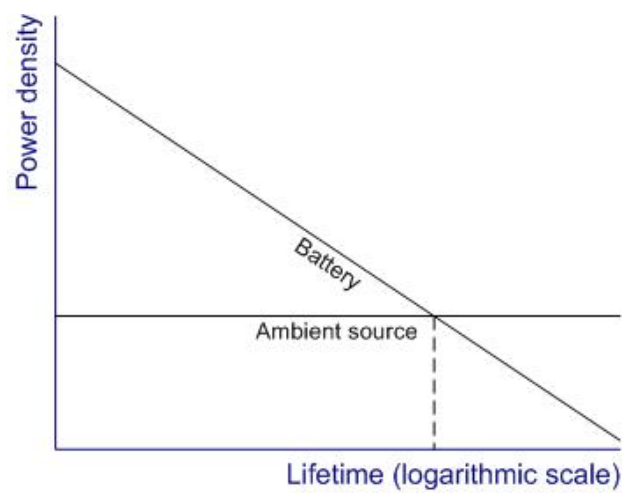

Figure 4. Power density versus lifetime for batteries and ambient sources.

\section{DESIGN EXAMPLES}

We present generic design examples to compare the use of primary batteries against optical energy. A power metric is used over a lifetime of 5 years (estimated lifetime of rechargeable batteries). Power inefficiencies due to the power and energy conditioning stages (Fig. 3) are not considered at this point. 
Two ambient situations are considered: outdoors (solar energy) and indoors (artificial light). For the node, two different power profiles are considered.

\section{A. Node}

The node and its power source must fit within a cube enclosure of $1000 \mathrm{~cm}^{3}$ and $10 \mathrm{~cm}$ edges. An EM250 transceiver is selected (Table I). Two operation modes are considered: continuous and periodic with $D=0.1 \%$. Table II shows $P_{\text {average }}$ and the consumed daily energy $\left(E_{\text {day }}\right)$ in both operation modes. For the sake of simplicity, we assume that the sensing and processing stages (Fig. 1) do not contribute to the power consumption.

TABLE II. POWER AND DAILY ENERGY CONSUMPTION OF THE NODE

\begin{tabular}{|l|l|l|}
\hline \multicolumn{1}{|c|}{ Operation mode } & \multicolumn{1}{|c|}{$\boldsymbol{P}_{\text {average }}(\mathbf{m W})$} & \multicolumn{1}{c|}{$\boldsymbol{E}_{\text {day }}(\mathbf{m W h})$} \\
\hline Continuous & 108 & 2592 \\
\hline Periodic $(D=0.1 \%)$ & 0.111 & 2.664 \\
\hline
\end{tabular}

\section{B. Optical energy}

Optical energy includes the electromagnetic spectrum form infrared to ultraviolet light. Indoor power density (mainly coming from artificial lights) typically ranges from $100 \mu \mathrm{W} / \mathrm{cm}^{2}$ to $1000 \mu \mathrm{W} / \mathrm{cm}^{2}$, and outdoors can be up to $100 \mathrm{~mW} / \mathrm{cm}^{2}$. Solar cells can be monocrystalline, polycrystalline, amorphous silicon or thin film, and their efficiency can be up to more than $30 \%$ [7].

Outdoors, at the area of Barcelona (Spain), in December (lowest irradiation month), 3.4 $\mathrm{PSH}^{1}$ can be expected ${ }^{2}$. Indoors, we assume $500 \mu \mathrm{W} / \mathrm{cm}^{2}$ during $8 \mathrm{~h}$ (e.g. in offices). Table III summarizes these data together with the daily energy and average power densities at the output of a solar cell with a 10 $\%$ efficiency.

TABLE III. ENERGY AND POWER DENSITIES FROM A SOLAR CELL

\begin{tabular}{|c|c|c|c|c|}
\hline Location & $\begin{array}{c}\text { Irradiation } \\
\left(\mathrm{mW} / \mathrm{cm}^{2}\right)\end{array}$ & Hours (h) & $\begin{array}{c}\text { Daily energy } \\
\left(\mathrm{mWh} / \mathrm{cm}^{2}\right)\end{array}$ & $\begin{array}{c}\text { Average } \\
\text { power } \\
\left(\mathrm{mW} / \mathrm{cm}^{2}\right)\end{array}$ \\
\hline Outdoors & 100 & 3.4 & 34 & 1.42 \\
\hline Indoors & 0.5 & 8 & 0.4 & 0.017 \\
\hline
\end{tabular}

\section{Primary batteries versus solar cells}

Table IV compares the required size of both primary batteries and solar cells in order to power the node. We assume lithium primary batteries with an energy density ${ }^{3}$ of 0.8 $\mathrm{Wh} / \mathrm{cm}^{3}$. A lifetime of 5 years is considered, which results in an average power of $18 \mu \mathrm{W} / \mathrm{cm}^{3}$ for the batteries. Sizes are given in square centimeters for solar cells and in cubic centimeters for batteries.

${ }^{1}$ Peak Solar Hours: equivalent hours with a radiation of $1000 \mathrm{~W} / \mathrm{m}^{2}$ or 100 $\mathrm{mW} / \mathrm{cm}^{2}$

${ }^{2}$ Average irradiation in December from 2002 to 2007. From [8]

${ }^{3}$ Average value from seven commercial batteries
Power densities are similar for indoor solar cells and batteries. On the other hand, outdoor solar cells provide 80 times more power and then provide the minimum size solution. Regarding to Fig. 4, the lifetime intersection point is slightly more than 23 days and 5 years when comparing the selected primary battery technology with the considered solar cells at respectively outdoors and indoors.

For continuous operation, both indoor solar cells and battery sizes are too large to fit respectively on the top (face of $100 \mathrm{~cm}^{2}$ ) and within the given enclosure. For periodical operation all the solutions fit in the required space, so other criteria such as cost and circuit complexity can be taken into account.

TABLE IV. PRIMARY BATTERIES VERSUS SOLAR CELLS

\begin{tabular}{|c|c|c|c|}
\hline \multirow[b]{2}{*}{$\begin{array}{l}\text { Energy } \\
\text { source }\end{array}$} & \multirow[b]{2}{*}{ Power density } & \multicolumn{2}{|c|}{ Power supply size } \\
\hline & & $\begin{array}{c}\text { Continuous } \\
\text { operation }\end{array}$ & $\begin{array}{c}\text { Periodical } \\
\text { operation }\end{array}$ \\
\hline Solar outdoors & $1.42 \mathrm{~mW} / \mathrm{cm}^{2}$ & $76 \mathrm{~cm}^{2}$ & $0.078 \mathrm{~cm}^{2}$ \\
\hline Solar Indoors & $0.017 \mathrm{~mW} / \mathrm{cm}^{2}$ & $6480 \mathrm{~cm}^{2}$ & $6.7 \mathrm{~cm}^{2}$ \\
\hline Battery & $0.018 \mathrm{~mW} / \mathrm{cm}^{3}$ & $5913 \mathrm{~cm}^{3}$ & $6.1 \mathrm{~cm}^{3}$ \\
\hline
\end{tabular}

\section{Energy storage}

Energy harvesters in general and solar cells in particular need an energy storage unit (Fig. 3). Here, we assume that the storage unit has to power the node for 5 days in darkness ${ }^{4}$. Table $\mathrm{V}$ shows the resulting sizes for lithium and $\mathrm{NiMH}$ secondary batteries and supercapacitors.

Energy density of batteries is two orders of magnitude higher than that of supercapacitors. As a result, supercapacitors are not feasible when the node is operating continuously.

TABLE V. ENERGY DENSITY AND REQUIRED SIZES OF STORAGE UNITS

\begin{tabular}{|l|c|l|l|}
\hline \multirow{2}{*}{ Storage units } & \multirow{2}{*}{$\begin{array}{c}\text { Energy } \\
\text { density } \\
\left(\mathbf{m W h} / \mathbf{c m}^{3}\right)^{\mathbf{a}}\end{array}$} & $\begin{array}{c}|c| \\
\text { Continuous } \\
\text { operation }\end{array}$ & $\begin{array}{c}\text { Storage unit size } \mathbf{( c m}^{\mathbf{3}} \mathbf{b}^{\mathbf{b}} \\
\text { operation }\end{array}$ \\
\cline { 3 - 4 } & $416(195-532)$ & 31 & 0.032 \\
\hline $\mathrm{Li}$ & $260(151-410)$ & 50 & 0.051 \\
\hline SiMH & $4.8(3.8-6.4)$ & 2700 & 2.7 \\
\hline
\end{tabular}

a. Average energy density obtained from 7, 13, and 3 commercial models of Li and NiMH batteries, and supercapacitors, respectivelly. In parenthesis appears the range.

b. Size is calculated with the average energy density.

\section{IMPLEMENTED NODES AND EXPERIMENTAL RESULTS}

An environmental WSN, REALnet, has been deployed at our Campus [9]. Fig. 5 shows the current state, where $\mathrm{C} 1$ is the coordinator node, R1 to R3 are router nodes and S1 is a sensor node for the measurement of the level and temperature of the Campus pond. Router nodes also perform some measurements. All the nodes include an ETRX2 module (Telegesis), which is based on an EM250 transceiver (Ember). Central node is placed indoors and is mains powered, router nodes are solarpowered (outdoors) and fixed in Campus lampposts, and sensor node is powered by primary batteries and attached at one of the

\footnotetext{
${ }^{4}$ This can be equivalent to one week of 1 PSH days outdoors (cloudy days) or a long weekend indoors
} 
walls of the Campus pond. No indoor solar powered node has been implemented yet.

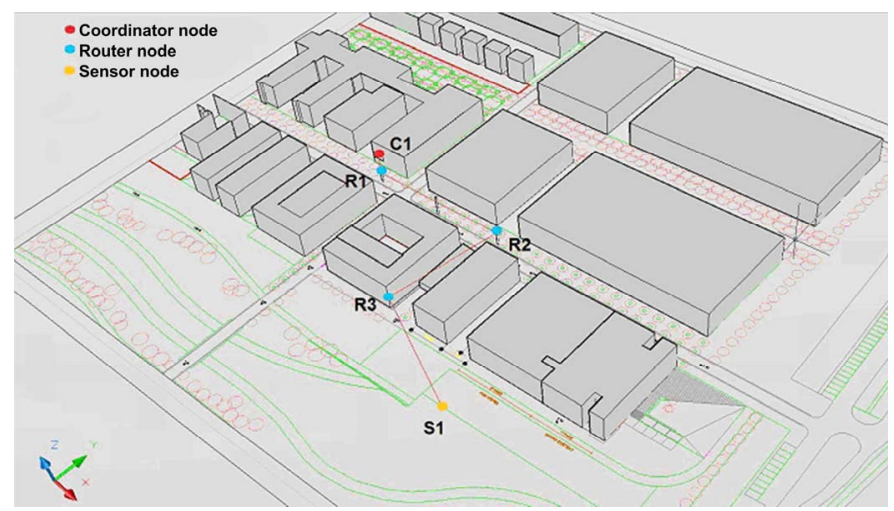

Figure 5. Current deployment of REALnet, an environmental WSN.

Table VI shows the three types of implemented nodes that will be fully described in this section. Because the transceiver accepts a broad range of voltage supply and disposes of an internal voltage regulator, external voltage regulators are avoided to reduce the complexity and cost. Then, batteries with a voltage range within the supply voltage range of the transceiver have been used. Now, for the sake of simplicity, the consumed average current $\left(I_{\text {average }}\right)$ and daily charge $\left(Q_{\text {day }}\right)$ will be used in place of $P_{\text {average }}$ and $E_{\text {day }}$, when designing the power supply of the nodes.

TABLE VI. IMPLEMENTED NODES

\begin{tabular}{|c|l|l|l|}
\hline & \multicolumn{1}{|c|}{ Node 1 } & Node 2 & \multicolumn{1}{c|}{ Node 3 } \\
\hline Power source & Outdoor solar & Battery & Outdoor solar \\
\hline Operation mode & Continuous & Periodic & Periodic \\
\hline
\end{tabular}

\section{A. Solar power}

Nodes 1 and 3 are solar powered. Fig. 6 shows a simple electrical model and $I-V$ graph of a solar panel (array of solar cells). $I_{\mathrm{sc}}$ and $V_{\mathrm{oc}}$ are respectively the short-circuit current and open circuit voltage, and $I_{\text {mpp }}$ and $V_{\text {mpp }}$ are respectively the current and voltage at the maximum power point (MPP). These data are normally provided by manufacturers at several irradiations. As can be seen, current and then power sharply decrease for $V>V_{\mathrm{mpp}}$.

An MPP tracker circuit, placed between the solar panel and the storage unit, permits to work at the MPP and then extract the maximum power from the solar panel. However, this adds complexity and has not been implemented at this point. In its place, the configuration of Fig. 7 was adopted, where $V=$ $V_{\mathrm{D}}+V_{\mathrm{B}}$ and the Shottky diode $\left(V_{\mathrm{D}} \approx 0.3 \mathrm{~V}\right)$ avoids the discharge of the battery. Additionally, a protection circuit to prevent the overcharge and undercharge of the rechargeable battery was implemented. $V_{\mathrm{B}}$ changes with the SoC of the battery. Then, in order to work in the region where $V<V_{\mathrm{mpp}}$, where the power decreases smoothly with decreasing values of $V$, we force $V_{\mathrm{mpp}} \approx V_{\mathrm{D}}+V_{\mathrm{B}, \max }$ by choosing a suitable solar panel. In addition, outdoors, the solar panel must comply: $I_{\mathrm{mpp}}>$ $Q_{\text {day }} / 3.4(\mathrm{PSH})$.

\section{B. $\quad$ Node 1}

This node type corresponds to any of the router nodes $\mathrm{R} 1$ to $\mathrm{R} 3$ in Fig. 5. It is solar powered, operates continuously $\left(Q_{\text {day }}=\right.$ $864 \mathrm{mAh}$ ), and relays the data of the sensor node to the central node. Two AA-size $2.7 \mathrm{Ah}(\mathrm{NiMH}$, rechargeable) batteries (Ansmann) connected in series were used as the energy storage unit. NiMH batteries were preferred to lithium-type batteries because of its lower cost and simpler charging schemes. These batteries can power the node more than three days in darkness. In sunny days, a low DoD (Depth of Discharge) is expected, which is reported to increase the number of charging/discharging cycles of rechargeable batteries and then their working life [6]. The operating output voltage range of the two-battery unit ranges between $2.8 \mathrm{~V}\left(V_{\mathrm{B}, \max }\right)$ and $2.2 \mathrm{~V}$, so within the supply voltage range of the ETRX2 module.
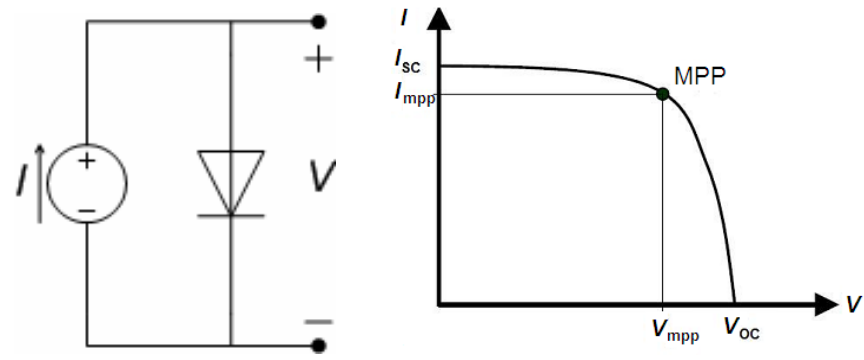

Figure 6. Electrical model (left) and generic $I-V$ graph (right) of a solar panel.

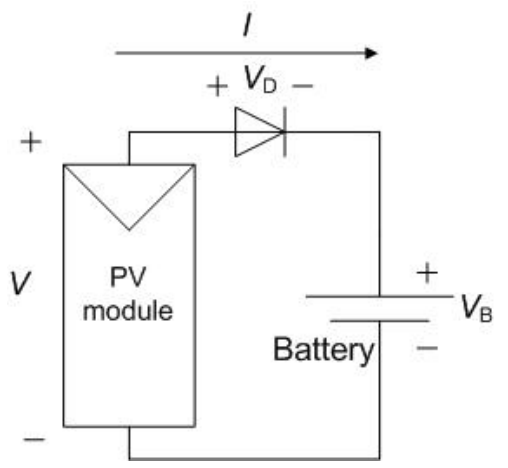

Figure 7. Selected configuration for the solar panel and rechargeable battery. The Shottky diode prevents the discharge of the battery.

A solar panel with $V_{\mathrm{mpp}} \approx 3.1 \mathrm{~V}$ and $I_{\mathrm{mpp}}>254 \mathrm{~mA} @ 100$ $\mathrm{mW} / \mathrm{cm}^{2}$ was required. Two MSX-005 (Solarex) solar panels $\left(I_{\mathrm{mpp}}=150 \mathrm{~mA}\right.$ and $\left.V_{\mathrm{mpp}}=3.3 \mathrm{~V}\right)$ connected in parallel $(2 \times$ $150 \mathrm{~mA}=300 \mathrm{~mA}$ ) were selected. External size of each panel is $147 \mathrm{~mm} \times 79 \mathrm{~mm} \times 10 \mathrm{~mm}$, with an effective solar area of $96 \mathrm{~mm} \times 57 \mathrm{~mm}$.

An IP66 enclosure (Rolec) was selected (Fig. 8). Its size $(200 \mathrm{~mm} \times 110 \mathrm{~mm} \times 60 \mathrm{~mm})$ was big enough to contain the printed circuit board (PCB) with the components and the rechargeable batteries disposed at the bottom. The solar panels, stuck to the top of the enclosure, slightly protruded. Solar panel current, internal enclosure temperature, and battery voltage are measured and transmitted to the central node.

An implementation with primary batteries requires a capacity of $315 \mathrm{Ah} /$ year. For a period of 5 years a capacity of 
$1578 \mathrm{Ah}$ is then needed, which can be achieved, for example, with 83 D-size lithium cells from Tadiran. This solution, obviously, does not fit within the selected enclosure and is cost-prohibitive.

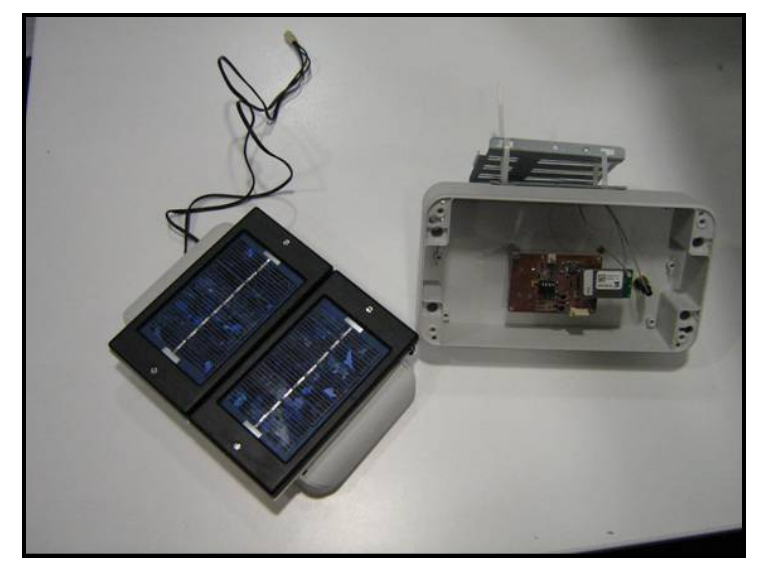

Figure 8. Node 1. The PCB with the batteries mounted at the bottom fits within the enclosure. Solar panels are mounted on the top.

\section{Node 2}

This node type corresponds to the sensor node (S1 in Fig. 5). It is powered with primary batteries although solar nodes are an option in this case. The node periodically activates every two hours. In about $14 \mathrm{~s}(D=0.2 \%)$, it measures the level (capacitive sensor) and temperature (thermistor) of the Campus pond and transmits the information to the central node through the router nodes. Measurements are performed with a direct sensor interface [10] using an ATtiny 2313 microcontroller $(\mu \mathrm{C})$. The $\mu \mathrm{C}$ also controls the periodic activation via its internal clock. Now, $I_{\text {active }}=38 \mathrm{~mA}, I_{\text {sleep }}=9$ $\mu \mathrm{A}$, resulting in $I_{\text {average }}=85 \mu \mathrm{A}$ and $Q_{\text {day }}=2 \mathrm{mAh}$. We selected two AA-size primary lithium batteries (L91, Enegizer) of capacity $3 \mathrm{Ah}$, so a runtime of 4 years can be achieved. Batteries were connected in series presenting a voltage range from $3.2 \mathrm{~V}$ to $2.8 \mathrm{~V}$, which fits within the supply voltage range of the microcontroller $(3.6 \mathrm{~V}$ to $2.7 \mathrm{~V})$ and transceiver. The same enclosure of node 1 has been used (Fig. 9).

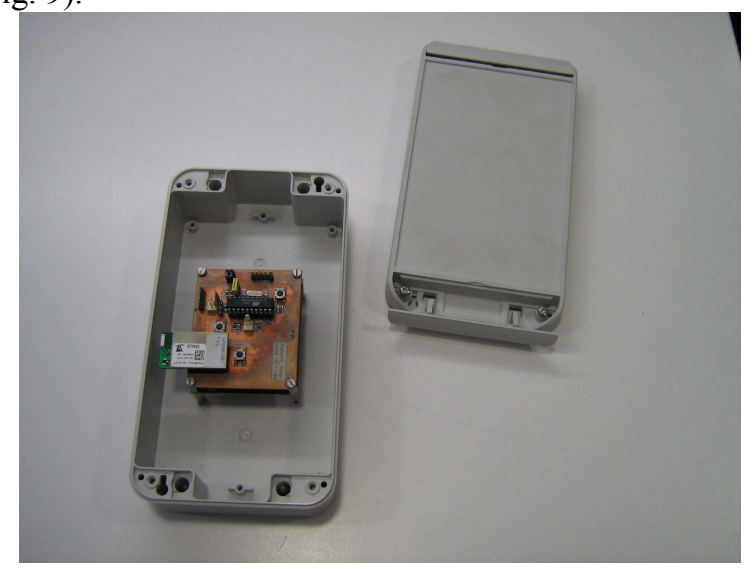

Figure 9. Node 2. The PCB with the batteries mounted at the bottom fits within the enclosure.

\section{Node 3}

This node type is a router node that operates periodically and is powered with solar panels. The node has not been incorporated to REALnet yet. An Atmel $\mu \mathrm{C}$ was also used to control the periodic $2 \mathrm{~h}$ activation in order to relay the data of the sensor node. Drift between $\mu \mathrm{C}$ internal clocks because of differences in temperature $\left(-10^{\circ} \mathrm{C}\right.$ to $\left.50{ }^{\circ} \mathrm{C}\right)$ and supply voltage $(2 \mathrm{~V}$ to $3 \mathrm{~V})$ can be up to $\pm 2 \%( \pm 144 \mathrm{~s}$ for a period of $2 \mathrm{~h}$ ). Then, the node is programmed to be active $288 \mathrm{~s}$ before the $2 \mathrm{~h}$ period. Then, the maximum active time will be $302 \mathrm{~s}$ $(288 \mathrm{~s}+14 \mathrm{~s})$ resulting in $D_{\max }=4.2 \%$. Now, $I_{\text {average, } \max }=1.6$ $\mathrm{mA}$ and $Q_{\text {day, } \max }=38 \mathrm{mAh}$. A Varta V250H battery pack (two button $250 \mathrm{mAh}$ batteries connected in series) was used. It offers low internal impedance $(920 \mathrm{~m} \Omega)$ and can work up to $65^{\circ} \mathrm{C}$. This capacity permits a low DoD, increasing the battery life, and to power the node for six and a half days in darkness. Furthermore, in case the node loses the synchronization with the sensor node, it can wait awake $6.5 \mathrm{~h}$ in order to recover it.

A solar panel with $V_{\mathrm{mpp}} \approx 3.1 \mathrm{~V}$ and $I_{\mathrm{mpp}}>10.5 \mathrm{~mA}$ is required. Two tiny solar panels (Ixys XOB17-04x3, $22 \mathrm{~mm} \times$ $7 \mathrm{~mm} \times 1,4 \mathrm{~mm}$ ) connected in series were used. Each solar panel has a typical $V_{\mathrm{mpp}}=1.53 \mathrm{~V}(2 \times 1.53 \mathrm{~V}=3.06 \mathrm{~V})$ and $I_{\mathrm{mpp}}=11.7 \mathrm{~mA}$.

An IP67 enclosure (Fibox) was selected (Fig. 10). Its size $(110 \mathrm{~mm} \times 80 \mathrm{~mm} \times 65 \mathrm{~mm})$ was smaller than that used for the other nodes. In this case, the solar panels occupied only a small portion of the available space at the top of the enclosure. An even smaller enclosure can be chosen if the dimensions of the printed circuit board and components are reduced.

A solution with primary batteries would need a capacity of nearly 66.6 Ah for a period of 5 years. Two DD-size batteries (from Tadiran) connected in parallel $(2 \times 35 \mathrm{Ah})$ can be used but do not fit within the selected enclosure.

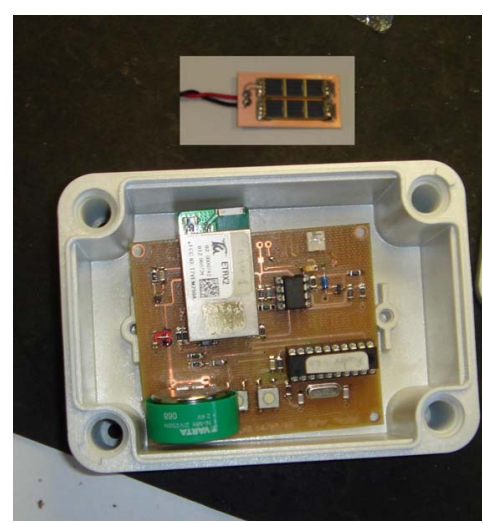

Figure 10. Node 3 . The size of the solar panel is now much smaller.

\section{E. Experimental results}

Fig. 11 shows the measured solar panel current, battery voltage, and temperature of the router node R1 (Fig. 5) during 8 days, from May 28 to June 5, 2008. As can be inferred from the top graph, all days were sunny, except May 31 that was a cloudy day. Whenever the solar panel current increased, so did the battery voltage and temperature. Maximum current was 
above $300 \mathrm{~mA}$; battery voltage ranged between $2.85 \mathrm{~V}$ (the programmed maximum voltage to prevent the overcharge of the battery) and $2.5 \mathrm{~V}$ (well above the set minimum voltage that activates the undercharge protection circuit); maximum internal temperature was below $30{ }^{\circ} \mathrm{C}$, and $5^{\circ} \mathrm{C}$ to $10^{\circ} \mathrm{C}$ above the ambient temperature. Data from the remaining router nodes (R2 and R3) show similar data. Preliminary tests (not shown) with node 3 show good agreement with predicted results.
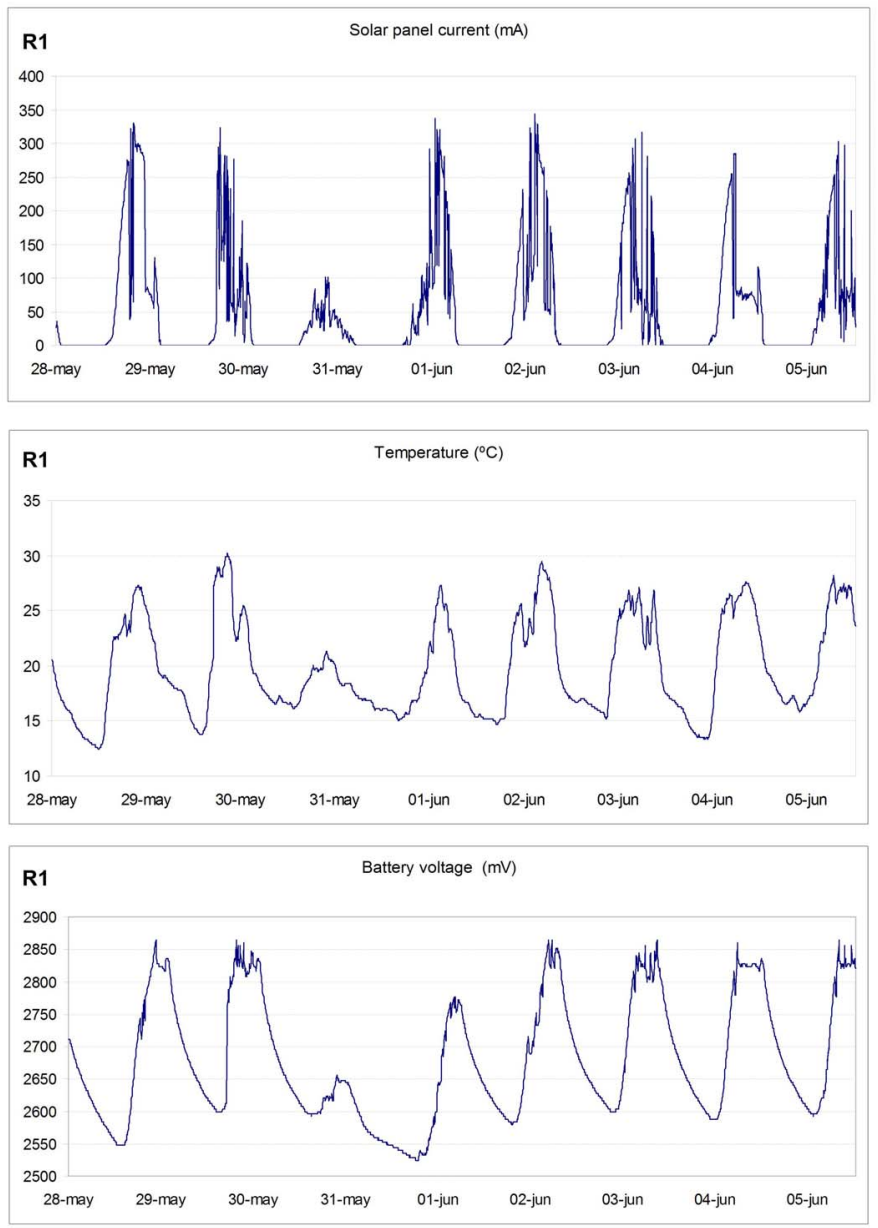

Figure 11. Router node: solar panel current, battery voltage, and temperature of the router node $\mathrm{R} 1$ measured during 8 days.

\section{CONCLUSIONS}

We have compared the use of primary batteries against energy harvesting, in particular with solar energy. Basic principles to power sensor nodes have been first outlined. Then, some general design examples have been presented. Solar energy clearly outperforms batteries outdoors, and can be an alternative indoors. For nodes operating continuously, only outdoor solar power can offer a suitable solution whenever small size is required. Finally, three types of nodes implemented for a current deployed WSN have been illustrated. Two of them are outdoor solar powered and one battery powered. Experimental results show the performance of one of the solar powered nodes.

\section{ACKNOWLEDGMENT}

The authors acknowledge the technical support of Francis López.

\section{REFERENCES}

[1] V. Raghunathan, S. Ganeriwal, M. Srivastava, "Emerging techniques for long lived wireless sensor networks," IEEE Communications Magazine, vol. 44, pp. 108-114, April 2006.

[2] M.T. Penella and M. Gasulla, "A review of commerical energy harvesters for autonomous sensors," in Proc. IMTC, Warsaw, Poland, May 1-3, 2007.

[3] M.T. Penella and M. Gasulla, "Battery squeezing under low-power pulsed loads," in Proc. I2MTC, Victoria, Canada, May 12-15, 2008.

[4] S.F.J. Flipsen, "Power sources compared: The ultimate truth?," Journal of Power Sources, vol. 162, pp. 927-934, November 2006.

[5] S. Roundy, P.K. Wright, and J. Rabaey, "A study of low level vibrations as a power source for wireless sensor nodes," Computer Communications, vol. 26, pp. 1131-1144, July 2003.

[6] D. Linden, Handbook of Batteries, 2nd ed. New York: McGraw-Hill, 1995.

[7] M. A. Green, K. Emery, Y. Hishikawa, and W. Warta, "Short Communication Solar cell efficiency tables (version 33)," Progress in Photovoltaics: Research and Applications, vol. 17, pp. 85-94, 2009.

[8] [Online] Available: http://www.soda-is.com/.

[9] J. Albesa, R. Casas, M.T. Penella, M. Gasulla, "REALnet: An environmental WSN testbed," in Proc. SensorComm, Valencia, Spain, 14-20 Oct. 2007, pp.502-507.

[10] F. Reverter and R. Pallàs-Areny, Direct sensor to microcontroller interface circuits. Barcelona: Marcombo, 2005. 